\title{
FADING GLORY?
}

\author{
Decision-making around the Project - How and Why 'Glory' Projects Fail \\ Svetlana Cicmil and Derek Braddon
}

\section{Section 1:}

\section{Introduction and positioning}

In this chapter we wish to focus on the practice of governing relationships, collaboration and decision-making around the project, where 'project' is understood as a label for a complex process through which participants jointly accomplish a sophisticated cooperative task, declared or approved as worthwhile, or strategically important. We are primarily concerned with large-scale multi-party projects which are linked to significant investment decisions, as these are inevitably in the public eye and exposed to general scrutiny (Trapenberg-Frick, 2008). These projects are surrounded by an aura of glory in rhetoric - a narrated promise of extreme prosperity ${ }^{1}$. They are often born out of vanity, or human ambition (Rehn, 2006), and associated with engineering, scientific, or managerial achievements. Promised, declared and expected benefits of these projects relate to a large number of people and their livelihoods, so it is hard to question them (Trapenberg-Frick, 2008), but their work processes and development (neither always visible nor reported) often adversely impact on an equally large number of people and their livelihood often adversely. They are costly - and often underestimated (Flyvbjerg, Bruzelius and Rothengatter, 2003), and controversial socially, environmentally, or politically. Moreover, the aura of glory is likely to create and perpetuate a specific decision-making rationality with "a political dimension that can capture the imagination of political leaders and the public" (Trapenberg-Frick, 2008, pp.242-3).

Such is the scale and risk associated with these large-scale glory projects that today they can only be undertaken by coalitions of firms, working together on a temporary basis, and drawing upon vast financial, human and technical resources, frequently requiring the involvement of government. This makes for a very complex, and sometimes unclear managerial structure for governing project decision-making and control, where project ownership and accountability become clouded by the different agendas of individual members of the project coalition, and the degree to which they genuinely have shared goals (March, 1989). The majority would agree with the statement that the core purpose of project governance is to evaluate and shape the development of the project throughout its life cycle in such a way that its outcomes remain safe, strategically aligned and beneficial to the stakeholders, as agreed at the time of approval (Miller and Lessard, 2008; Priemus, Flyvbjerg and van Wee, 2008). A good governance system is expected to contribute to making clear project goals, accountabilities and performance measurements (Hart, 1995; Samset, 2008). However, reports on spectacular abandonment and failures of major extolled projects in the public domain are abundant globally ( Ford,2011; Lewis, 2011a; Lewis, 2011b; Sheridan, 2011). The business pages of daily newspapers continually illustrate the widespread misgoverning of collaboration, evaluation and risk appraisal that has had significant,

\footnotetext{
${ }^{1}$ A definition of 'glory' in the Collins Concise Dictionary, 1999, $4^{\text {th }}$ ed. HarperCollins Publishers
} 
undesired, or catastrophic consequences for specific groups of project stakeholders, whose interests were always supposed to be protected by the project governance process.

How such major projects, with a need for extensive intra-coalition collaboration, are governed becomes a key issue, and draws into the spotlight relational characteristics of a project coalition, such as the exercise of market power and political declaratory powers, accountability and transparency in decision-making and contract enforcement, opportunistic behaviour and intra-coalition trust. It has been acknowledged that structural interventions (modifications in contractual forms) alone are insufficient in dealing with the inherent paradox and complexity of multi-organisational projects. (Cicmil and Marshall, 2005; Clegg, Pitsis, Rura-Polley and Marossheky, 2002).

It is not surprising, therefore, that the governance of projects has been a popular and widely researched topic. Some excellent insights into, and debates about theory and practice of the governance and decision-making around mega projects have been published in recent years, including the work of Flyvbjerg, Bruzelius and Rothengatter (2003), Klakegg, Williams and Magnussen (2009), and the collections by Priemus, Flyvbjerg and van Wee (2008), Hodgson and Cicmil (2006), and Pryke and Smyth (2006), to list only a few. This chapter builds further on these ideas and propositions about the problems with governing the risk appraisal and approval of mega projects and collaborative behaviour of participants, where both project governance and the project itself are seen as an interconnected social arrangement - a web of complex relationships among stakeholders. The aim is to advance the extant understanding of governance failures, by combining pragmatic theoretical conceptualisations with concrete empirical analyses in order to identify and address, in ways that matter, problems that are important for the affected individuals and communities, according to Flyvbjerg's (2001) redefinition of the purpose of social organisational research. Our theoretical repertoire spans ideas from complexity thinking, political economy and social organisational theory. As our focus is on the issue of values and power in context, we build our argument on the case of a glory project: the UK's National Health Service 'National Programme for Information Technology' (NPfIT) and, in particular, the implementation of the Lorenzo medical care records computer system, having reconstructed it entirely from publicly available reports. Ultimately, the alarming implications of the abandoned project for a range of project stakeholders justify this focus.

\section{Information technology implementation projects}

Information Technology/Information Systems (IT/IS) projects have been a topic of intensive research and scrutiny globally since the early 1980s (Thomsett, 1980), because of the aura of dissatisfaction with their performance (Cadle and Yeates, 2001). For example, McManus and Wood-Harper (2008) examined project abandonment and failure, focusing on 214 new information systems projects launched across the European Union (EU) during the period 1998 to 2005. Critically, only one in eight information technology projects launched in this period can be considered truly successful. Yet, despite such a high failure rate, huge sums continue to be invested in information systems projects, which are eventually written off. Across Europe in 2004, for example, the cost of IT systems project failure amounted to some $€ 142$ billion. This study has highlighted governance issues behind the failures relating to: the choice of contract; insufficient risk management, lack of management judgement; poor communication between stakeholders; poor contract management; and poor delegation and decision-making (political agenda, lack of transparency in risk appraisal). McManus and 
Wood-Harper (2008) provided detailed insights into the potential causes behind IT project failure, and confirmed why a cautious approach should always be taken to promises attached to new IT software development, in whichever sector it may apply. Their evidence suggests that key aspects of a project (such as leadership, stakeholder and risk management issues) are not factored into projects early on, in many instances cannot formally be written down for political reasons and are rarely discussed openly at project board or steering group meetings, although they may be discussed at length behind closed doors. A considerable proportion of delivery effort results in systems that do not meet user expectations and are subsequently cancelled.

Turner and Cochrane (1993) insist on understanding the specific nature of unpredictability, risk and project management challenges associated with projects which are conceived to enable implementation of IT/IS and other sophisticated or novel technology. Particular issues are: the intangibility of both predicted outcomes and indicators of project progress; the unpredictability of technological innovation (fast changes over time) and its impact on people in the given context: and resulting difficulties with agreeing on requirement specification early in the project life cycle. Acknowledging such uncertainties, according to Turner and Cochrane, is crucial for designing and establishing the systems of governance, risk appraisal and control of IT/IS projects - which is essentially relational, assuming trustworthiness and openness of the experts involved, their commitment to the wider project benefits, transparency in configuration development and changes, and care for the ultimate user.

In exploring the question of why organisations "embark on questionable ventures and then persist with them well beyond an economically defensible point" (Drummond, 1999, p.11), escalation is defined as irrational persistence in response to such predicaments, a situation in which costs are being incurred, negative feedback received, where there is an opportunity to withdraw or to persist, but the consequences of withdrawal or persistence are uncertain (Ross and Staw, 1986). The interplay of social and structural pressures, as well as psychological and project-related factors, is shown to be behind escalation of commitments, where decisionmakers inherit a previously unsuccessful and long-established decision (as distinct from involvement in an ad hoc venture).

\section{Conceptualising complexity, accountability and project governance}

"The formation and operation of projects essentially relies on a societal infrastructure which is built on and around networks, localities, institutions and firms." (Grabher, 2002, p.211)

Cicmil and Marshall (2005) offer a view on project governance as a form of collective engagement in project work, where agency and structure are interrelated, simultaneously constructing and reproducing one another over time. The authors claim that governance frameworks with regulatory intentions are not, in practice, enacted in a linear manner. As the project unfolds, as new goals are formulated and as new knowledge is created to achieve these goals, influence spontaneously arises in webs of power relationships within the project, as people interact intensively in order to create meaningful forms of activity that move things on. According to Cicmil and Marshall (2005), project artefacts, both rhetorical and technological, varying professional expertise and other forms of micro-diversity, , simultaneously define, reproduce and change over time the identities of project participants and their power relations, obligations and expectations in an unpredictable manner. As a result, the governance of complex projects often evolves into a process of reconciliation of 
conflicting feelings of anxiety, scepticism, moral duty and contractual commitment. On the ground, it also always involves regulating and mediating human action through laws, procedures and institutions.

Cicmil and Marshall (2005) conducted an in-depth study of the impact of innovative contractual forms on team integration and performance of construction projects through the theoretical lens of complex responsive processes of relating (Stacey, 2001; 2003). They identified three interrelated and ever present aspects of projects that present challenges to project governance, and argued that governance processes must explicitly acknowledge and address such complexity in order to fulfil their governing aim effectively. These aspects are ${ }^{2}$ :

- The ever present complex dynamics of interaction and power relationships among diverse project actors, making the problem of agency (behaviour of organisational actors/project members) and structure (the boundary of project organisation) inseparable over time, and interfering with the processes of control and evaluation of work;

- Ambiguity and equivocality of strategic expectations, project outcomes and project performance criteria among the members of the project coalition, making the notion of shared project goals problematic in practice;

- The consequence of time flux i.e. inevitable changes over time within the contexts in which the project and its stakeholders are situated, combined with the specification changes, unpredictability of the outcomes and the resulting anxiety about facing the 'unknown'- makes project plans an unreliable reflection of the actuality of the project, and makes traditional approaches to risk management and project control paradoxical.

Mirroring broader definitions of governance (Monks and Minow, 1995), we find it helpful to understand project governance as the relationship between various parties in determining the direction and performance of projects over time, and, as Miller and Lessard (2008, p.169) point out, "a set of decision-making processes and methods for accumulating of knowledge [sic.] to ensure that creativity and discipline are brought to bear". The creation of relationships that allow a project to be reconstituted and to proceed, even after major changes in project drivers and the resulting payoffs to the various parties involved, is essentially about risk sharing and accountability (Miller and Lessard, 2008; Flyvbjerg et al., 2003). This makes the assertion by Hugo Priemus and his colleagues critically important for our analysis:

"Successful projects are not selected but shaped. Successful sponsors appear to start with project ideas that have the potential to become viable. These sponsors then embark on shaping efforts to influence risk drivers ranging from projectrelated issues to broader governance. The seeds of success or failure of individual projects are thus planted early and nurtured over the course of the shaping period as the choices are made. Risk is inherently linked to the choices made and moral responsibility for the action taken." (Priemus et al., 2008, p.5)

\footnotetext{
2 see also Cicmil, Williams, Thomas and Hodgson (2006); Cicmil, Cooke-Davies, Crawford and Richardson (2009).
} 


\section{Collaboration, transparency and commitment in an IT/IS mega-project coalition}

"Contracts will always support a greater or lesser degree of interpretative flexibility, and this becomes particularly relevant at times of commercial conflict when different parties attempt to lay claim to contractual legitimacy by presenting their interpretation as a 'true' meaning" (Clegg, Pitsis, Marossheky and RuraPolley, 2006, p.223)

Trapenberg-Frick (2008) argues that the technological sublime ${ }^{3}$ plays an instrumental role in the decision-making processes within project governance. It has the potential to fuel creative design, engineering and public involvement, and also optimism (bias) about "the ability of design and engineering to overcome the technical complexities associated with implementing large-scale projects" (Trapenberg-Frick, 2008, p.259) that often lead to time and cost escalation.

Drummond (1994; 1999) scrutinised a number of risky initiatives, including a major IT/IS project implementation disaster (the London Stock Exchange's Taurus initiative). In similar fashion to Trapenberg-Frick (2008) and Flyvbjerg (1998; 2003), she warned that the early stages of such risky initiatives, when they are declared and approved as projects, are crucial, because the decisions taken at that point become increasingly difficult to reverse as time goes by. Through the resulting 'means/ends reversal', the project becomes an end in itself, compounded by the difficulty of rational examination of interim outcomes, progress and risks, and decision-makers being so obsessed by the original commitment that they make sub-optimal choices as a result. Drummond illuminates the ethical, social and psychological aspects of such escalation, noting "the imbalance between the power and responsibility" (1999, p.14). According to Flyvbjerg (2008, p.137) "The consequence is a Machiavellian make-believe world of misrepresentation", which makes it extremely difficult to decide which projects deserve support and which do not - not quite a risk management practice we would wish to see.

An important insight from Drummond, exploring the Taurus project, is the escalatory spiral of decisions around risky ventures "whereby one sub-optimal decision forces another until the resultant 'stuck up' becomes catastrophic" (Drummond, 1999, p.15), illuminating a paradox of attempting to control IT/IS implementation in a linear manner. In effect, Drummond exposed the limitations of conventional axioms of large-scale IT/IS project governance to account for and address the impact of preoccupation with assumed possibilities of powerful technology on the decision-makers' rationality. Very little thought tends to be given to a wider notion of project complexity, as discussed earlier, which explicitly acknowledges non-linearity, flux, paradox and unpredictability. Accountability for potential risk escalation and failure, and moral responsibility for choices and their consequences are rarely made explicit.

The interplay of the technological sublime and radical unpredictability of IT/IS development and implementation makes the governance of major IT/IS projects exceptionally challenging. This complexity, highlighted in Turner and Cochrane's (1993) argument and conceptualised as the three interrelated aspects (Cicmil and Marshal, 2005), is inherent in projects conceived upon IT/IS implementations, and should never be overlooked in the process of their

\footnotetext{
${ }^{3}$ We borrow the notion of the technological sublime from Trapenberg-Frick (2008, p.239) who defines it, after Nye (1994:xvi) as being about :' repeated experiences of awe and wonder, often tinged with an element of terror, which people have had when confronted with particular natural sites, architectural forms and technological achievements'.
} 
governance. Their intangible outcomes cannot be specified nor, for that matter, committed to in advance without a proper collaborative (rather than opportunistic) approach to risk sharing. Non-linear iterative change management processes and psychosocial aspects (escalation, conspiracy of optimism, the technological sublime and power and politics surrounding them) require a strong focus on relational dynamics, ethics of collaboration and accountability of decision-makers for choices made.

What would it mean to effectively govern temporary multi-party project coalitions that are formed to accomplish the project work and deliver the expected benefits amid conflict, sublime-bounded rationality and uncertainty? Opportunistic behaviour (Ive and Rintala, 2006) in project coalitions results from information, power and knowledge asymmetry related to radical unpredictability, emergence and evolution (incompleteness of plans) as well as fragmentation of work (specialisation); cooperative intentions and ability to perform as expected due to multiple agendas, understanding of key performance indicators; interpretations of contract; and power and politics in executing project control. With a fertile soil for opportunistic behaviour already in place, the key governance challenge of glory IT/IS projects becomes the complex organisation of inter-organisational collaboration, through contracts and informal social mechanisms to curb opportunism, to facilitate accomplishment of the required project work and to involve key stakeholders in evaluating project progress, whilst protecting their interests where necessary.

The notions of long-term unpredictability and micro diversity run counter to the conventional notion of 'ordering' (attempting to regulate patterns of behaviour through structural interventions) in the pursuit of project goals, successful project completion and an improved planning process which programmes, in advance, the unfolding of project work. From this point of view, it is necessary to rethink the possibility of predetermined success criteria for a project, the controllability of the interconnected project activities to achieve the desired end in advance of them happening, and the kind of governance mechanisms (contracts) promoted as effective guardians of diverse stakeholder interests, planned action and risk strategies.

Miller and Lessard (2008) argue for an alternative type of project governance that relies on partnerships, cooperation, or relational contracts, rather than rigid specification-based traditional competitive tendering, as more adequate for the high level of unpredictability and dynamics inherent in the planning, development and execution of complex projects. Van Marrewijk, Clegg and Pitsis (2008) and Clegg et al., (2002) discuss technologies, methodologies and contractual arrangements for governing projects with multiple parties and stakeholders that have been developed, introduced and promoted. This would include a number of alternative arrangements, such as the Private Finance Initiative (PFI), PrivatePublic Partnerships (PPP), Build Own Operate Transfer (BOOT) alliances, and focusing on risk sharing to curb the opportunism of lowest cost tender so that the risk is allocated to the party best able to manage it, building in a strong incentive for managing risk at the lowest cost and gaining rewards through such management.

Pragmatically, contracts have a threefold function, to enable:

- Work transfer (to define the work that one party will do for the other)

- Risk transfer (to define how the risk inherent in doing the work will be allocated between the parties) 
- Motive transfer (to implant motives in the contractor that match those of the client; to minimise opportunistic behaviour by offering incentives for collaborative behaviour)

However, the contractual framework, as a codified set of rights and responsibilities regulating collaboration can never capture, in advance of them happening, all the various situations that will occur over time, nor provide instructions for what should be done. Therefore they leave some scope for interpretation and discretion, which often results in a fight among the parties concerned over the 'true' meaning of a certain clause.

It is widely believed that effective governing of a complex project can ultimately be achieved through building a collaborative commitment and transparency into the moral fibre of a project. Informal social mechanisms can facilitate socialisation of project monitoring, control and commitment, by creating a common ground, common rationality negotiated between the parties on the basis of reputation, history of relationships, future opportunities and current formal contractual clauses and other dimensions of the complex project network. This common ground, fragile and in constant flux, yet able to stabilise collaboration at a practical level, encapsulates the notion of trust, defined as mutual understanding "...taken to signify and represent a co-ordinating mechanism based on shared moral values and norms supporting collective co-operation and collaboration within uncertain environments" (Knights, Noble, Vurdubakis and Willmott, 2001, p.313).

Clegg et al. $(2002 ; 2006)$ argue that unless an exclusive culture of "collaborative envisaging of the future" is established and so maintained "by design" (a mixture of a partnering oriented contractual strategy and specific 'culture controlling' mechanisms) for the project as an independent entity, it will evolve into a time-bomb, an arena for continuous competitive renegotiation of the micro-diversity, and subcultures and fights for dominance. Therefore, a significant challenge for project governance is the structure/agency problem of prioritisation and focus between the social and the technological, i.e. how the project contracts are distributed (structure), and how human interaction (agency) develops as a consequence of the organising process within the project coalition. It is not unusual in some economic/political contexts that a parasitic chain of several companies (from local government downwards) can evolve, receiving a 'rent' based purely on their connections, and doing practically no project work at all. "By the time the first shovel of cement enters the mixer, the actual budget that remains allows for only the cheapest labour and often inferior materials". (Lewis, 2011b, p.17).

Drummond (1994) notes that structural and contractual influences on governing project collaboration are particularly pronounced when involvement in the project spreads, via subcontracting in the procurement process, and responsibility for the initial decision becomes detached from individuals. Commitments made often become sunk costs, while political pressures from outside investors or trade unions often emerge for reasons other than financial performance.

\section{An analytical framework}

Mirroring broader definitions of governance (Monks and Minow, 1995), we find it helpful for the forthcoming analysis of the concrete project case to understand project governance as the relationship between various parties in determining the direction and performance of projects over time, or, as Miller and Lessard(2008, p.169) point out, "a set of decision-making 
processes and methods for accumulating of knowledge [sic.] to ensure that creativity and discipline are brought to bear". Furthermore, our review of, and deliberations about, relevant theoretical concepts strongly implies that the creation of relationships that allow a project to be reconstituted and to proceed - even after major changes in project drivers and the resulting payoffs to the various parties involved - is essentially about risk sharing and accountability (Miller and Lessard, 2008; Flyvbjerg et al., 2003). This has informed our analytical framework for studying the apparent mis-governance of a recent, ambitious software development and implementation initiative in the UK public sector, the NPfIT, shedding new light on the behavioural and structural influences on decision-making which brought this project to its (publically declared) collapse and demise. In summary, we are particularly interested in examining two phenomena:

- The interplay between the publically exalted nature of the original grand idea and the rationality and accountability behind subsequent project approval and risk appraisal decisions;

- Processes put in place to organise project collaboration, control its dynamics, and ultimately prevent opportunistic tendencies and morally unacceptable behaviour of the key project participants, typical of this kind of project.

\section{Section 2:}

\section{Misfortunes of Lorenzo - The NHS IT project}

In this section we outline the key features of the Lorenzo project, one of two main computer systems (the other being Cerner's Millenium system) that form key constitutive elements of the $£ 11.4$ billion NHS National Programme for IT. The Lorenzo case has been specifically reconstructed for the purpose of this chapter from information in the public domain, and will provide an empirical background for our analysis and conceptual deliberations in Section 3 of this chapter.

Lorenzo is a software system, designed and developed originally by the UK firm, iSOFT, but now owned through takeover by the Virginia-based US multinational, Computer Sciences Corporation. (CSC). The original plan was to provide every NHS patient with his or her own electronic care record, which could then be made available by computer link to different parts of the NHS, so that medical staff could access accurate, up to date records on demand and whenever required. The estimated overall cost was expected to be in the region of $£ 7$ billion.

What began in 2002 as an admirable objective has, a decade later, turned into a major project disaster. A huge amount of public money has been spent on the new care records system, despite the fact that the project has been riddled with major system delivery delays and massive cost over-runs almost since its inception. Finally, in September 2011, the Government effectively abandoned the National Health Service Programme for IT and its central project, Lorenzo. According to the Independent newspaper, this major IT project was:

"meant to revolutionise the way the Health Service worked. But far from heralding in a new age of efficiency, the National Programme for IT is now widely perceived as the greatest government IT white elephant in history. As well as the huge costs involved, suppliers have walked away, projects are running years behind schedule, while medical 
professionals have complained that they were never consulted on what they wanted the new system to achieve." (Laurence, 2010).

\section{The initial stage: contracts and risk assessment}

Ministers clearly recognised at the launch of the Lorenzo project that it was a highly risky venture as, at that stage, the suppliers did not actually have a tried and tested product to deliver. However, risk assessments had clearly been carried out by the Department of Health. As The Times reported in 2011:

"The risks of failure attached to the $£ 11 \mathrm{bn}$ scheme to create a national patient database were concealed from MPs and the public. According to a leaked document seen by The Times, civil servants estimated at the start of the project that there was a one-in-three chance that software would be delivered late." (Kennedy, Pitel and Homann, 2011).

How far these risk assessments and their implications for the NHS were ever actually discussed fully with Ministers at the time remains unclear, since the same newspaper also reported that:

"In a surprising admission which raises questions about the level of scrutiny of the IT fiasco, the Department of Health said last night: "we understand that this risk assessment was not shared with Ministers'.” (Pitel, Smyth and Kennedy, 2011).

This document, leaked to The Times and dating apparently from 2008, contained a risk assessment under which a project score of 41 or above would indicate high levels of risk. As The Times noted late in 2011:

"The implementation of NHS computerisation was wildly out of the safe zone with a score of 56. In a remarkable omission, officials failed to include any figure for the cost of cancelling the programme when assessing the risks of termination."(Pitel, Smyth and Kennedy, 2011).

Contracts for the NPfIT project, when launched in 2002, were only offered to a few, very large computer companies, despite the fact that IBM, the world's largest software consulting group, had considered it too extensive and complex a project to contemplate. Presumably this strategy appeared sensible to Ministers precisely because NPfIT was correctly perceived as being such an ambitious and far-reaching project that it would take the major players in the industry to deliver it successfully. However, since contracts were to be allocated to bidders on a regional sole provider basis across England, this meant that the four original suppliers Accenture (North East and East Midlands), Fujitsu (South), Computer Sciences Corporation (North, Midlands and East) and BT (London) - would effectively each hold a regional monopoly. As a result:

"Smaller companies specialising in health computing were frozen out of the market place and either went out of business or moved into other fields. As a result, there is 
now little or no competition available to maintain the software." (Smyth and Kennedy, 2011).

The contractual deficiencies within the Lorenzo project, which have become increasingly evident over its lifetime, include one further weakness, which could represent a financial time-bomb for the NHS. The original contracts with these large computer companies to install Lorenzo run out around 2015, after which they apparently have no obligation to carry out maintenance. Under what The Times has called "zombie contracts", responsibility for maintenance and its funding will then have to move, directly or indirectly, to the NHS Trusts, who will have to negotiate new maintenance deals with exactly the same companies which failed to implement the Lorenzo system on time and to budget, and whichnow face little real competition in the market. To cite The Times again:

"This burden will put a squeeze on the Trusts, which are already under pressure to find $£ 20$ bn of efficiency savings. Records show that it will need around $£ 2.1 \mathrm{~m}$ to cover the estimated costs of maintaining the systems. The Trusts will have little choice but to stick with the main providers, BT and the American giant CSC, which have been criticised by auditors and MPs for poor delivery." (Smyth and Kennedy, 2011).

In criticising the contract formulation process at the heart of the NPfIT and Lorenzo projects, it is important to appreciate that this process took place in an environment where the Department of Health was under immense political pressure to deliver rapid and successful outcomes.

Papers obtained by Computer Weekly in 2008 under the Freedom of Information Act showed that the Department of Health completely misjudged how long it would take to deliver the Lorenzo project and make electronic patient records available online. At a meeting in Downing Street on $18^{\text {th }}$ February, 2002, attended by the major IT providers, policy advisers and health professionals, the Department of Health promised that the systems would provide "seamless" care across the NHS by 2004/05, approximately half the time later allotted to the scheme. The Computer Weekly evidence, however, suggests that the political time-line for successful Lorenzo implementation was even tighter, and that the Prime Minister, Tony Blair:

" repeatedly sought to shorten the timetable for the NHS IT which would have brought visible benefits in time for a general election in May 2005. Blair told the meeting that implementing the programme faster than planned would underpin the Government's reform agenda and provide evidence of NHS modernisation to the public." (Ritter, 2008).

This political pressure was maintained, despite the fact that, at the time, access by patients and doctors to national summary care records was only at the trial stage, and contracts for the delivery and implementation of new national systems had been agreed as far ahead as 2013 . Perhaps not surprisingly therefore:

"The Department of Health awarded a series of contracts in record time under the NHS's National Programme for IT in 2003, but some suppliers complained they were being given too little time to consider their proposals. The main part of the programme - a national electronic health record - is running three years behind the original timetable, in part because the idea is more difficult than first thought to put into practice. The papers raise questions about whether the timetable for the NPfIT was geared towards a general election, 
rather than the practicalities and complexities of the scheme - and whether the Department of Health put politics before realities in promising the programme in less than three years." (Ritter, 2008).

Finally, there is also evidence that poor contract negotiation and formulation by the Department of Health at the start of the project was responsible for its damaging impact on the NHS at the level of individual Trusts. As The Times reported:

"The programme's contracts were so poorly negotiated that the Government was obliged to deliver enough Health Trusts to the suppliers or pay compensation instead. One Trust was forced to choose a less attractive and dearer IT system, or face a $£ 9 \mathrm{~m}$ cut in its budget." (Pitel, Smyth and Kennedy, 2011).

\section{The Suppliers}

As noted above, the Lorenzo project relied on a small number of key suppliers, each of whom had a different business agenda to be pursued and objectives to be gained from their involvement in the project.

Under great political pressure, contracts were drafted, as quickly as possible, to large, mainly American, companies from an 'approved' list - essentially comprising major players in the computer systems sector. These contractors, however, had virtually no experience of the UK NHS. Their experience was primarily in the very different world of private health care in North America. Another approved supplier, BT, although a British company, had little direct experience of the health care sector either.

Smaller specialist companies were, as noted above, effectively excluded from the project, and those larger companies who were given a contract would simply be dropped from the project, if they failed to deliver. This suggests that there was clearly no real sense of commitment to the contractors concerned and, hence, little chance that they would, in turn, feel a sense of 'project ownership' or responsibility. Not surprisingly, after a time, some suppliers wanted to leave the programme, while others spent significant sums to persuade other contractors to take over their previously agreed responsibilities.

Problems with the main suppliers began to show themselves in 2007. In July 2007, Accenture withdrew from the project. Following its withdrawal, most of its responsibilities were transferred to the CSC Alliance. The Fujitsu Alliance held responsibility for client cluster in the South until May 2008, when their contract was formally cancelled. Health service IT decision-makers had become increasingly concerned about Fujitsu's progress with the project. In March 2004, Fujitsu signed a £900m contract to deliver systems to 17 Acute Trusts, 36 Community Trusts and 8 Mental Health Trusts. With only one system having been installed, Fujisu's contract had to be renegotiated; contract negotiations broke down in 2008 and Fujitsu's role in the project was terminated. Even now, in 2012, the UK Department of Health remains in legal dispute with Fujitsu over the 2008 contract termination for the South of England cluster, potentially one of the largest ever civil actions in the UK, that could see the Department facing legal liabilities of more than $£ 1$ bn (Ehealthinsider, 2011). In response to the criticisms of its performance, the company has stated that "it is "proud of the excellent work it did' on the programme" (Pitel, Smyth and Kennedy, 2011).

Within two years of the initial project launch, then, half of the key suppliers to the programme had either pulled out, or had their contracts terminated. Since May 2008, only two IT providers remain in place for the main body of the programme: the CSC Alliance and BT. As well as the major casualties in the project team noted above, several other smaller 
companies, working in alliance with the major players, have also come to grief. In August 2005, for example, IDX Systems Corporation lost its position in the Fujitsu Alliance in the Southern cluster, due to repeated failure to meet project deadlines, and was replaced by the Cerner Corporation. In 2006, ComMedica's contract with the North West/West Midlands cluster was terminated and, somewhat ironically, the company was replaced by GE Healthcare (the new owners of the IDX Systems Corporation).

The experience of the CSC Alliance, a key player in the Lorenzo project, illustrates further supply problems with the implementation of the system, and the legacy issue that often accompanies single-supplier dependence. In 2008, the CSC Alliance was awarded a $£ 3$ bn contract to replace Accenture by the Department of Health, and was tasked with implementing the new electronic patient record software in 166 NHS trusts in three major clusters throughout England. Initially, CSC made good progress delivering 'interim' systems to hospitals in primary and community care, but was then unable to fulfil its agreement to deliver the leading-edge Lorenzo integrated patient record software on schedule (with the exception of a few pilot sites). In February 2011, CSC was held to be in breach of contract by the Department of Health for its inability to meet a series of Lorenzo deployment deadlines, culminating in September 2011 with the Department finally terminating what remained of the original NPfIT programme.

The UK National Audit Office has recorded over three thousand defects with the Lorenzo system and its implementation, and the MP, Richard Bacon, a member of the Public Accounts Committee, has described the Lorenzo project as:

"one of the most egregious mistakes (of the NHS IT saga)....I hadn't heard of the term 'vapour ware' at the time but that's what it was. It hadn't been written. It was just an idea in somebody's head." (Kennedy, Pitel and Homann, 2011).

That key suppliers can create such havoc with leading-edge computer software installations particularly in such sensitive areas as the Health Service, for more than a decade is bad enough. The supplier situation is, however, even worse, at least with regard to the CSC Alliance, for three reasons. First, the NHS refused to provide information about the company's poor performance, requested under the Freedom of Information Act, in case:

"disclosure might damage the US manufacturer's share price” (Pitel, Smyth and Kennedy, 2011).

Secondly, CSC is seeking a £2bn "extension of its contract after it failed to deliver fully functional software to any of the 166 NHS Trusts in England" (Pitel, Smyth and Kennedy, 2011) Apparently, CSC had:

"boasted in a Wall Street filing that it expected an extension of its contract to provide electronic patient records and that the British Government was unlikely to sack it in light of the risk and cost of a lawsuit from the Americans." (Pitel, Smyth and Kennedy, 2011).

Thirdly, there is now a suggestion that CSC actually knew three years before the termination of the Lorenzo project that it could not deliver the on-line patients record system in line with its contract. The information was unearthed by Canada's second largest pension fund, Ontario Teachers, which is suing CSC for their disastrous performance in the Lorenzo project. As the Sunday Times reported late in 2011, Ontario Teachers had stated that:

"According to Lorenzo's deputy head of testing, Lorenzo was never the correct software for the job." (O’Driscoll and O’Connell, 2011). 
The same newspaper report alleges that, in 2008, CSC sent an internal audit team to the UK and India to investigate the Lorenzo project. The team apparently concluded that CSC could not deliver the NHS contract from a technology and operating perspective. The same newspaper also cites an e-mail from a senior CSC executive in the UK later that year, concluding that: 'the project was on a death march' (O'Driscoll and O'Connell, 2011).

Clearly, at the very least, the Department of Health failed to get the best out of its suppliers. CSC has not yet delivered the bulk of the systems for which it is contracted and has, instead, implemented a large number of interim systems as a stop-gap strategy. It is now an accepted fact that the implementation of the new NHS records system, built around iSoft's Lorenzo software, has proved to be a technical and financial disaster, not just for the NHS, but for the supplier as well. In six devastating months in 2011, iSoft was forced to issue three profit warnings, admitted a further two-year delay in the delivery of its revised software package and, most seriously, became mired in revelations of accounting irregularities and a Financial Services Authority inquiry. Eventually, the company was taken over by one of its main customers, the CSC Alliance, in August 2011. This takeover has important implications for the NHS and its future plans, as it now guarantees that CSC will benefit directly from new maintenance contracts to be issued in the future for the electronic records systems. As The Times noted:

"CSC spotted the potential value of maintenance deals many years ago .and....had been keen to buy the rights to maintain the computer programs from the business.........SC had no rights to the maintenance of the solution after the expiry of the contract. It got them by buying the company" (Smyth and Kennedy, 2011).

The cost here for the Trusts that assume responsibility for maintenance after 2015 may well be substantial. In the same news article, for example, The Times commented that Oxford and Buckinghamshire Mental Health Trust have estimated additional costs of $£ 350,000$ each year for six years to maintain the system after 2015 .

The other remaining supplier, BT Healthcare, has also had its share of problems, and has also apparently been unable to deliver against its original contract. The Department of Health eventually agreed a revised contract, reducing the number of systems and increasing the price for each system BT had to deliver. In the view of the Public Accounts Committee in 2011:

"The Department is clearly overpaying BT to implement systems: BT is paid $£ 9$ million to implement systems at each NHS site, even though the same systems have been purchased for under $£ 2$ million by NHS organisations outside the Programme." (PAC, 2011).

The Committee also noted the difficulties experienced by BT in:

"delivering care records systems, particularly in acute hospitals, have required the Department to significantly revise its approach in London, moving away from delivering standard systems towards more locally tailored products. The introduction of local tailoring has, however, resulted in significantly higher costs. The Department has removed half of acute trusts, all GP practices and the London Ambulance Service from its contract with BT but this significant reduction in scope has led to cost reductions of just $£ 73$ million against a contract value of over $£ 1$ billion. (PAC, 2011). 
In 2008, BT replaced Fujitsu in the South of England cluster and, once again, the Department of Health had to change its approach to delivering these systems.

\section{Section 3:}

\section{Sublime rationalities, the paradox of cooperation and the challenge of managing advanced technological expertise}

We discussed earlier in this chapter the fact that the governance of glory projects is ultimately about uncertainty communication, i.e. the negotiation of risk sharing strategies, responsibilities and accountabilities for choices made, and for actions emanating from them. The body of empirical evidence available for the analysis of the Lorenzo project indicates some major omissions and failings. For example, the possibility of cancelling the programme was ignored as uncomfortable and hence non-discussable, and was not included in assessing the risks of termination. The risks of failure (e.g. software implementation delay) appear never to have been discussed properly and were virtually concealed from MPs and the public by the Department of Health (DoH). There is always a risk with interpreting information and making decisions about something that is not yet tangible -such as Lorenzo. This project, like so many others, fell into such a trap. Below, we analyse it in more depth.

\section{From the sublime promise to the failure to consult properly}

The very name of the overall NHS IT initiative - The National Programme for IT - and its initially approved budget, the investment of $£ 11.4$ billion, "to provide every NHS patient with his or her own electronic care record which could then be made available by computer link to different parts of the NHS so that medical staff could access accurate, up to date records on demand and whenever required", resonate with our discussion of the ambition and sublime surrounding glory projects. The original promise, captured by a number of similar statements in the public domain, seems to have served as the principal mechanism for engaging the public with the idea. Pronouncements about the revolutionary intent, a longawaited solution to an undeniable problem, carrying unquestionable, admirable benefits to medical staff and NHS patients alike, can be captivating and irresistible. The determination of the project promoters to harness the potential of technology for providing solutions to problems for which they are held responsible (i.e. to revolutionise the way the health service works in a new age of efficiency demanded within the political arena) is obvious in these statements. However, despite the visibly significant impact of the initiative on a large number of people and their jobs, wellbeing and safety, it remains unclear what kind of consultation process actually took place at any stage of the project as part of the governance process to engage with NHS professionals and other potential systems users.

Richard Granger, appointed in 2002 as director general of the NHS IT programme, was given the job of turning the national programme into reality. However, as MP Richard Bacon commented in a speech in the House of Commons on 14 June 2011:

"Mr Granger had no patience with what he saw as special pleading by medical staff, whom he believed were unwilling to accept the ruthless standardisation that was necessary to deliver the advantages offered by the IT system. He effectively believed that he knew what the clinicians needed better than they did themselves." (Hansard, 2011). 
Despite this, many clinicians were determined that they would have an effective input into the decision-making process, and Dr Anthony Nowlan, the health informatics expert and, at the time, the executive director of the NHS Information Authority, was asked to ensure this happened. The aim was to:

"obtain a professionally agreed consensus about what was the most valuable information to store, and what was achievable in practice” (Hansard, 2011).

In practice, however, while this user-led requirement consensus was completed and included in the specifications, it apparently played a very minor part. In reality, as Bacon noted:

"The large majority of the so-called output-based specifications, and the crucial major hospital systems at the heart of the programme, were developed without involvement and scrutiny by the leadership of the health profession. That happened despite the fact that involvement by users is essential if one wants software that works and that people will use." (Hansard, 2011)

Indeed, Dr Nowlan is on record before the Public Accounts Committee as stating that:

"it became increasingly clear to me that efforts to communicate with health professionals and bring them more into the leadership of the programme were effectively obstructed." (Hansard, 2011)

Perhaps the least satisfactory aspect of the failure to communicate fully with end-users of the system during its early development came about when Dr Nowlan was asked to produce a list of all those people who had been involved in specification work, so that project reviewers could see for themselves the degree of consultation that had apparently taken place. As Bacon observed:

"in fact, all that had happened was that an e-mail had been sent out. Quite understandably, Dr Nowlan thought that saying that people had been consulted because they had been sent an e-mail was not consultation in any proper sense, any more than compiling a list of people who had been sent an e-mail was proper validation. He regarded the claims as a sham, and refused to co-operate." (Hansard, 2011).

The blueprint for the NHS IT reforms was published in June 2002, entitled: 'Delivering 21st century IT support for the NHS: national strategic programme', with the aim of connecting NHS healthcare with the capabilities of modern information technology. Citing Richard Bacon MP again:

"There was, however, an odd discrepancy at the outset. At the back of the original document were four appendices, one of which contained the project profile model and stated that the project's estimated whole-life costs were $£ 5$ billion. It provided a total risk score of 53 out of a maximum of 72 . In other words, the project was very high risk. When the document was published, however, that project profile model had been removed and there were only three appendices - the likely costs of the project and the true risks were concealed right from the start." (Hansard, 2011) 
Here we see the 'dark side' of project concept evaluation (Flyvbjerg, 2008, p.136-7) illuminated in Wachs's (1989) study of 'lying planners': "the most effective planner is sometimes the one who can cloak advocacy in the guise of scientific or technical rationality" (Flyvbjerg, 2008, p.137). Instead of being open, communicative, participatory, and democratic, planning is often closed, an instrument of domination and control. Decisionmaking behind planning by definition should be about rationality but, according to Flyvbjerg (1998), it is often about power.

Lack of proper consultation about the project's purpose and expected outputs, and the absence of risk communication, at times bordering on deception and irrationality, has been highlighted as detrimental for projects in the work of Loosemore (2006); Flyvbjerg, Holm, and Buhl, (2005) and Drummond (1999), among others. The explanations are found in psycho-social, political, structural and ethical elements surrounding the given initiative which, in combination, form and simultaneously reproduce a specific shared ontology within which decision-makers make their choices, declare preferences and condone actions. The Lorenzo project, and for that matter the overall NPfIT did not escape this trap.

\section{Project Contracts and Structure: design for collaboration?}

Rehn's (2006) thesis that economies are systems of waste, overlap and excess, using efficiency only to waste in more glorious ways, is relevant here. The unfolding trauma of project failure, according to Rehn, is a mask for a more hard-to-handle truth: that we are engaging in creating follies. The aura surrounding the NPfIT and the Lorenzo project was 'revolutionary and exalted' in every sense from the start. So powerful was the ambition, that it excluded effective reality checks. The evidence of its impact on the Ministers' logic can be seen in the approval of procurement in 2002/3. The contract process itself exhibited a kind of desperate urgency which, in turn, opened up scope for opportunistic behaviour (see below). It is clear from the Lorenzo case study that contracts were offered, bid for and secured in a remarkably short time. Furthermore, there is clear evidence that the risk element associated with the project was hidden right from the start, even as contracts were being signed.

Contracts were awarded to 'a few, very large computer companies'- major players in the industry - as an assurance of successful delivery, a decision that has turned out to be detrimental to a number of smaller specialist companies, as well as to the ultimate delivery of the project. The collective optimism bias and rejection of uncomfortable risk assumptions under the spell of Lorenzo's sublime was fuelled by immense political pressure on DoH to deliver rapid and successful outcomes. The promise of 'seamless' care across the NHS by 2004/5 was obviously influenced by the timing of the general election scheduled for 2005 . This was the driving force for a rapid award of a series of contracts, the negotiation and formulation of which was completed during 2003, with irreversible consequences (to be discussed below). It was already clear by 2007 that both the project schedule and the delivery of the system with expected functionality were being compromised.

In May 2003, potential bidders had been presented with a 500 page specifications document and apparently told to submit bids within just five weeks. The great speed at which contracting was completed meant that all the complex issues had to be faced after the contracts had been let; in effect, a large number of key contracts were signed before the Government really understood what they wanted to buy, and those bidding to supply actually understood what was expected of them. The scale of mismatch between the contracted strategy and the radical uncertainty of the venture was immense here. It hardly formed the foundation for a successful major IT venture. 
As noted in the Lorenzo case study, the approach from the top appears to have been one where established IT market players would be awarded contracts on the basis that they should be able to deliver output on time and to budget, and, should any fail to do so, they were expendable and would be replaced. For example, Richard Bacon M.P. has noted that:

"Mr Granger made it clear that things would be different on his watch. Contractors would not get paid until they delivered, and those not up to the mark would be replaced. He even compared contractors to huskies pulling a sled on a polar expedition: 'When one of the dogs goes lame, and begins to slow the others down, they are shot. They are then chopped up and fed to the other dogs. The survivors work harder, not only because they've had a meal, but also because they have seen what will happen should they themselves go lame." '(Hansard, 2011).

The case explicitly illustrates the problem Drummond (1994) identified about a relational dynamics and unpredictability in a project increasing with the expansion of sub-contracting in the procurement process, making accountability and responsibility for the initial decision detached from individuals. The damage to the Lorenzo project caused by the exclusion of smaller specialist companies, and, crucially, the exodus of the key suppliers over time is explained in Section 2 (sub-heading The Suppliers). Moreover, a chaotic management of changing conditions within the delivery team did not contribute to "shaping and directing" of the project so that "creativity and discipline are brought to bear" (Miller and Lessard, 2008, p.169) and project outcomes assured to remain safe, strategically aligned and beneficial to the stakeholders.

Our analysis of the case has shown the failure of the contract negotiation and formulation process to ensure attainment of all three pragmatic functions of a contract, mentioned earlier in the chapter: work transfer; risk transfer; and to implant motives in the contractor that match those of the client, thereby minimising opportunistic behaviour by offering incentives for collaborative behaviour.

\section{Expert contractors, misplaced optimism and opportunistic tendencies}

We can also recognise here all the aspects of Drummond's (1999) dynamics of escalation of decision-making around a large-scale IT/IS implementation as a project resulting in an escalatory spiral of decisions, a means/ends reversal and paradoxical imbalance betweenpower and responsibility, with catastrophic consequences. There is little evidence that the governance of Lorenzo operated on the basis of knowledge of a wider picture of what goes on in social construction of IT/IS projects and project management. It seems that there was no analysis of who is included in, and who is excluded from, the decision-making process, what determines the position, agendas and power of different participants with respect to issues, and how these different agendas are combined and resolved in the process.

The Lorenzo project also provides a good example of misplaced optimism in glory project management. This can be found both in the overriding expectation of project leaders that poor performance in the past would suddenly be transformed into improved performance in the future, without a significant change of direction or purpose and, perhaps more important, in their effectively ignoring a succession of 'alarm bells' issued by those monitoring the project's development from the outside.

For example, in April, and again in October, 2006, the refusal of the Department of Health to make available to external monitors (including even MPs) concrete, objective information 
about NPfIT's progress prompted 23 leading UK academics and experts in computer-related fields, to raise concerns about the programme in two successive open letters to the Parliamentary Health Select Committee.

Again, in June 2006, a critical report from the National Audit Office concluded that "it was not demonstrated that the financial value of the benefits exceeds the cost of the programme." The report questioned whether the programme would ever actually deliver care records as planned, and noted that some of the renegotiated contracts had failed to show value for money. For example, the NAO found that the average cost of three new acute systems in the South was $47 \%$ more expensive than in London, where BT was also the key supplier. The NAO also concluded that, crucially, the Department of Health lacked fundamental management information on the number of systems delivered and the amount spent on each system, as well as the cost implications of changes to the contracts for the delivery of systems (NAO, 2006).

In the same year, a report from the British Computer Society (BCS, 2006) stated that "the central costs incurred by the NHS are such that, so far, the value for money from services deployed is poor." In April, 2007, a highly critical and detailed 175 page report on the programme was published by the Public Accounts Committee of the House of Commons. The Chairman of the Committee commented that "this is the biggest IT project in the world and it is turning into the biggest disaster." The Committee noted that key suppliers to the programme were struggling to deliver and would not be able to meet the planned schedule. Furthermore, it drew attention to the fact that Lorenzo still had to win the "hearts and minds" of NHS professionals, as there had been little detailed consultation with them at any stage of the project (PAC, 2007). Furthermore, a report from the Kings Fund, also in 2007, attacked the government for its "apparent reluctance to audit and evaluate the programme""(Kings Fund, 2007).

In a second report on NPfIT in 2009, the Public Accounts Committee noted that key project deliverables were "way off the pace", and the risks to the eventual deployment of the entire national system were "as serious as ever", primarily because "essential systems are late or, when deployed, do not meet expectations of clinical staff." (PAC, 2009).

In its third report on the programme, in 2011, the Public Accounts Committee noted with concern the problems they and the National Audit Office had:

" faced in getting timely and reliable information from the Department. Information provided has frequently been late, has contained inconsistencies and has contradicted other evidence" (PAC, 2011).

Finally, the Cabinet Office's major projects authority noted in 2011 that:

"The project has not delivered in line with the original intent as targets on dates, functionality, usage and levels of benefit have been delayed and reduced. It is not possible to identify a documented business case for the whole of the programme. Unless the work is refocused, it is hard to see how the perception can ever be shifted from the faults of the past and allowed to progress effectively to support the delivery of effective healthcare." (Cabinet Office, 2011).

The Cabinet Office authority concluded that : 
"there can be no confidence that the programme has delivered or can be delivered as originally planned", and that therefore Ministers should "dismember the programme and reconstitute it under new management and organisation arrangements." (Cabinet Office, 2011).

In consequence, then, after 10 years or more of obfuscation, delay, costly over-runs and, as MP Richard Bacon put it "a sense in 2008 that Ministers were spouting rubbish, saying everything was fine when it plainly wasn't" (Pitel, Smyth and Kennedy, 2011), the revolutionary reform programme for information technology in the NHS and its flagship Lorenzo project has ended in abject failure. Somewhat ironically, the providers of NHS care, such as hospitals and GP surgeries have now been effectively left to strike whatever IT deals they can afford with the same software installation companies that, between them, effectively destroyed the Lorenzo dream.

All responsibility for shaping and directing the project in order to ensure its outcomes remain safe, strategically aligned and beneficial to the stakeholders seems to have been abandoned, and replaced by inertia and inhibition of those who govern to react, oblivious to the 'alarm bells' and sense of impending disaster. The case shows irresponsible negotiation of contracts and no explicit addressing of 'fair' risk sharing, where a blind confidence in the ability of 'world experts' to deliver a glory project was (mis-)used by the experts, to behave opportunistically, with very little professional ethical or moral responsibility to the vulnerable stakeholders (GP practices, NHS services and staff, patients and taxpayers). The relational process of project governance 'turned on its head' and "the Government was obliged to deliver enough Trusts to the suppliers or pay compensation instead" (The Times, $9^{\text {th }}$ December, 2011,p.3), with opportunistic, low-performing contractors (CSC, BT Healthcare) receiving undue advantages.

An unbalanced combination of the penalties in contracts designed to protect the client, and the compensation rights designed to protect contractors involved in projects which are terminated, serve to create further complex problems in managing glory projects with intangible outcomes which are difficult to specify in advance. The Lorenzo case study provides a good example of the penalty/compensation dilemma. As The Guardian reported on October $4^{\text {th }}, 2011$, the Computer Sciences Corporation was paid some $£ 200 \mathrm{~m}$ in April 2011 by the NHS to cover the projected costs of delivering Lorenzo patient records to Trusts in the North, Midlands and East of England in 2012. But after the NHS declared itself unsatisfied with the progress of the work on September $30^{\text {th }}$, it requested the taxpayers' money back, and NHS Connecting for Health was re-paid some $£ 170 \mathrm{~m}$ by CSC.

Just over one week earlier, however, The Guardian also reported that:

"Ministers are considering offering one of the NHS's worst-performing IT contractors financial help to keep the company from ditching a troublesome software package which is 'not fit for purpose', according to Cabinet Office documents. The plan to offer the US group Computer Sciences Corporation (CSC) one last chance to fix the software risks a furious backlash over 'payments for failure', in the latest twist to a fiasco that has generated years of delays at considerable cost to the Health Service" (Bowers, 2011).

Here, then, lies the dilemma that intensifies the problems of contract management for glory projects and renders them almost impossible to terminate. First, the Department of Health declares that the Lorenzo project will be scrapped, as it is now not fit to provide the modern 
IT services that the NHS needs. Then, while the project itself is brought to an end, the DoH decides not to actually terminate existing contracts, even though CSC's plans for the Lorenzo software package are seen as undeliverable, and a long way short of the full functionality of the contracted solution. Part of the reason for this decision is that the $\mathrm{DoH}$ is still contesting a long-running feud with CSC over a £3bn agreement to install IT systems in the Midlands and in the North and East of England, and is concerned about potential legal action that may follow. However, the Cabinet Office report, mentioned in the Lorenzo case study and recently declassified, reveals that programmers are still having to provide 'bespoke' code changes to Lorenzo, months after its installation at Morecambe Bay, the first Acute Hospital Trust to take the system. Pennine Care Trust was also supposed to be a Lorenzo 'early adopter', but has pulled out. At the same time, in response to the criticisms of its performance, the key contractor has stated that "it is 'proud of the excellent work it did' on the programme'"(Pitel, Smyth and Kennedy, 2011).

Paradoxically, the resulting situation around Lorenzo is that there is now little or no competition available to maintain the software, turning a glory project into, effectively, a financial time-bomb for the NHS. Moreover, the governance of Lorenzo contracts and cooperation failed to live up to one of its most important responsibilities - to protect the vulnerable stakeholders, while allowing undue advantages to non-performing contractors. This paradox is encapsulated in the Lorenzo project, which illuminates how specialist expertise, opportunistic behaviour, (in-)competence to perform, the letter for original contract, the lack of accountability and basic moral responsibility for the conduct at all levels in the web of governing relationships, are so closely entangled.

The Lorenzo project, therefore, illustrates clearly how decisions around the project based on different rationalities, selective interpretation of information and persuasive powers linked to the possession of unique expertise, can undermine its chances of success. Furthermore, Lorenzo is not alone in this respect. For more than two decades, we have witnessed a succession of major complex IT projects encountering a predictable array of problems including: the tendency to exceed budget and schedule targets (sometimes involving massive discrepancies between planned outcomes and actuality in terms of cost and time profiles); the repeated experience of 'project creep' (attributable to the failure at the outset to set clear and manageable objectives for the project) ; the failure to consult fully with those most affected by the project's implementation, or to listen adequately to their views; the tendency to proceed with a project long beyond the point at which it is no longer viable or valuable (Cavendish, 2012); and an additional array of new and complicated management challenges that such projects inevitably create.

\section{Section 4: Key Insights and Concluding Remarks}

As discussed in the earlier sections of this chapter, the core purpose of project governance is to evaluate and shape the development of the project throughout its life cycle in such a way that its outcomes remain safe, strategically aligned and beneficial to the stakeholders as agreed at the time of approval. Can evidence of any of this be found in the Lorenzo case? What new light has our analysis shed on the process of glory projects governance? Why is this governance with its regulatory, disciplinary and moral accountabilities so easily 
abandoned in the case of glory projects, and how is it made possible time and time again? Is it only about the glory lost, or much more than that?

Firstly, we identified implications of an aura created around a project involving advanced technology for decision-making rationalities present in the Lorenzo governing process. On reflection, the project was approved without a rational reason or, perhaps, with seemingly irrational reasons. It was hard to challenge and question the decision, due to the project's technological sublime. Here an interplay of rationalities, power and lack of participation is visible. Yet, although Lorenzo would have had an impact on a large number of people, and their safety, careers and well-being, our analysis indicates a lack of transparent risk appraisal and its communication to the affected groups - a problem exacerbated by a rushed contract formulation. Here we encounter one of the classic failures in many large-scale IT projects the failure to consult adequately with potential system-users. Moreover, the absence of mechanisms for curbing typical conspiracy of optimism can also be noted. As a result, controversy and paradox increased on multiple fronts - managerial, social, environmental and political.

Another of the major problems identified in the forgone analysis of the Lorenzo project is the apparent absence of any evidence of effective attempts to shape and re-direct the project to induce discipline and accountability, let alone much-needed transparency. The analysis shows a clear failure to structure and organise the project coalition and control the dynamics of collaboration within it to prevent opportunistic and irresponsible behaviour of the key players. There are three key issues here:

\section{Problems with shaping the project:}

Contractual strategies of glory projects, even those advanced towards collaboration and partnerships, in practice often seem powerless to prevent opportunistic tendencies and profit seeking; mistrust; hidden costs to the public sector and the tax payer, and little accountability and transparency in the process of risk appraisal, sharing and management among the contractual parties during project execution. Our case confirms that the issues of politics, inertia and powerlessness are inseparable from experiences with glory projects. The necessary balance of strict contractual forms and informal mechanisms to cope with the simultaneous order and chaos of a complex IT/IS project, and ensure a collaboratively negotiated transfer of work, motive and risk, was not achieved for Lorenzo.

It seems that the rushed and instrumental approach to contract negotiation ignored the inherent non-linearity of project work unfolding over time (the complexity of IT/IS projects) thus omitting to ensure an adequate level of confidence in the contractors' collaborative behaviour. The assumed competence of the contractors to perform the expert work took priority over ensuring cooperative relationships and behaviour, ending with a misplaced reliance on the contractors' good-will and trust, with very few adequate control systems in place.

\section{Problems with re-directing the project:}

The analysis illuminated an unclear, inflexible, mixed-up decision-making structure around the project, with elements of escalation, unresolved conflicts of interest and undesirable merging of the roles of project promoter and guardian of public (stakeholders') interests in a single entity, discussed earlier. An important aspect here is a lack of timely risk reassessment and consultation to protect vulnerable stakeholders (taxpayers, patients, medical and other NHS staff on the ground), while allowing undue advantages to low-performing contractors. 
Problems with ensuring that accountability, creativity, transparency as well as discipline are brought to bear on the project:

In the analysis of the procurement and contract design of the Lorenzo project, there is no evidence of efforts to address the risk of power and paradox of technology-based expertise through adequate disciplining mechanisms, both formal (contractual) and informal (socialising), that may regulate collaborative behaviour and curb opportunism.

Our analysis of a large software development glory project initiative in the UK public sector sheds more light on the nature of project governance, and the process of governing such a complex project, amid reports of catastrophic failures of such projects elsewhere. It has confirmed the need for understanding the governance of glory projects as a social arrangement of complex human and institutional interactions, as the relationship process itself, not only as a system or mechanism of rules, available control procedures and their ordering effects based on neutral, rational and expert decision-making. It is difficult and unhelpful to separate the agency and structure in the practice of project governance, but it is useful to adopt a complexity lens that gives primacy to unpredictability, non-linearity and the paradox of human relations in these kinds of project settings.

\section{Recommendations}

Our exploration of decision-making around a large-scale glory mega-project such as Lorenzo raises several important questions. What does it mean in practice to govern mega-project collaboration among strangers in an inherently non-collaborative world? Does collaboration yield political and economic benefits that can be maximised through choice of a particular project collaborative framework? In particular, are the notions of 'mutual interest' and 'willingness to share risks' realistic in light of the disposition of human beings in their natural, self-preserving state to trust and cooperate, and if so, under what set of circumstances? How can any conflicting prioritisations and focuses be reconciled, for example, between individual agency versus organisational performance; between assumptions about the sameness/commonality of key concepts, such as values, expectations and culture, and about inter-connectedness in risk sharing and response (i.e. the idea that 'we are all in the same boat', regardless who generated the risk and for what gains)? This raises the issue of moral agency and action and, inevitably, the status of the individual agency versus corporate performance; in essence, what values or principles are most appropriate for managing collaborative glory projects ethically, and should collective actors as well as individuals in such ventures have moral status?

\section{Challenging the sublime}

The paradox of glory IT/IS projects seems impossible to eliminate without a radical rethink of the conventional wisdom. This firstly requires a need to reconsider conceptualising IT implementation as a traditional project, as the project form itself gives rise to misconduct, opportunism and poor governing process (Hodgson and Cicmil, 2006), and should include considering an alternative project life cycle model in planning, promoting and assessing the risks of these initiatives. The second step requires a shift in focus away from the sublime and 
the dream of technological promise and power associated with 'big' experts, towards an exploration of more appropriate ways (smaller scope, collaborative processes, or bounded ownership) of solving the problem of efficiency, even when it includes IT/IS projects. The final step must be to hold those responsible for allowing so many 'fading glory' projects to collapse (such as Taurus, the NATs Control system and Lorenzo) fully accountable for their choices in the face of an unknown future, and, in addition, morally responsible for any adverse impact of their decisions on the lives of an immense number of people who, inevitably, cannot be entirely shielded from the substantial risks that can never be completely eliminated from complex mega-projects.

A new governance approach would need to be able to address the causal ambiguities, interest conflicts and legitimacy issues (Suchman, 2000) that appear from time to time in all such sublime projects, and would need to abide by virtues of prudence and practical wisdom (Flyvbjerg, 2001). The choice of contract, the form of project organisation, and understanding its limitations are therefore key tasks for those governing the project. In reality, successful mega-project management requires a kind of 'virtual learning' for practitioner development, ensuring that all players attain appropriate skills in self-awareness, diplomacy, ethical, cultural and political aptness.

\section{Formal and informal contractual mechanisms}

With reference to literature and extant research (see Section 1) these crucial issues could be addressed through the adoption of a project governance system which combines a balance of stringent monitoring systems and informal (social relational) mechanisms. Such a governance process should ensure both transparency of commitment under unpredictability (relational, technological, economic) and contract enforcement. Moreover, due care needs to be given to the level of trust towards experts. Confidence in their non-opportunistic behaviour should be built realistically on the combined evidence of both their technical competence to perform, and their cooperative attitude. This can be achieved by balancing the assumed level of trust/good-will with control systems in place. Ultimately, however, the question remains: is ethical collaboration on revolutionary IT/IS projects in a global context possible, and, if so, how it should be governed (not just structurally formalised but socialised) in practice?

It may therefore be helpful to view decision-making within project governance - particularly in addressing the technological sublime - as an art form, as implied by Foucault's concept of the art of government and 'governmentality' as the design of a more collective and practical consciousness within which to make sense (Clegg et al., 2006). The art of governance of glory IT/IS projects can be understood, therefore, as an amalgam of technology, rationality and knowledge present (used and reproduced) in concrete project settings, providing the participating agents with the ontology (shared/negotiated reality), a way of being which determines what we see and therefore what is, for us, logical to do, or what is possible to achieve (Braun and Castree, 1998).

Viewing mega-project governance as a relationship-regulating process and at the same time as the relationship itself, we avoid separating the structure from the agency and acknowledge the importance of observing power asymmetries, complex interactions (opportunism, deception, cooperation, competition) and conflicting values in the given context, and acknowledge how the emerging nature of these, in turn, shapes and changes the governing regulatory framework. Crucially, mega-project governance does not happen in a vacuum, and it is the effectiveness of decision-making around a project that will ultimately determine its fate. 
We argue that the governance framework of glory projects should be understood, not as a 'stabilized' mechanism, structure, or system of control, but as heterogeneous and becoming, as a generic social technology, or spatial-temporal framework, a process"for institutionalising social habits and patterns of behaviour so that it then becomes possible for us to communicate with each other and develop practical norms" (Chia, 2002, p. 867)

that governs the joint action of members of project parties in otherwise chaotic, ambiguous and unpredictable reality.

A good deal of literature ( Stacey, 2001, 2003; Flyvbjerg, 2001; Raelin, 2001; Holt and Rowe, 2000; Bresnen and Marshall, 2000; Sydow and Staber, 2002; Chia, 2002; Weick, 2002) suggests that, in an unpredictable world where the outcomes of an action cannot be known in advance, managing should be seen as a process of continually rearranging the paradoxes of organizational life, through a different type of leadership. Similarly, Flyvbjerg argues for an approach to studying social practice in complex arrangements, by refocusing attention on the need for judgements and decisions made in a manner of virtuoso social and political action. The implied virtues of 'prudence' and 'practical wisdom' are inspired by the themes of politics, power, and situational ethics, while making judgements and decisions under radical unpredictability.

\section{The ethics of collaboration}

As our case study shows, it is difficult to escape or overlook the issue of ethics of collaboration and governance in dealing with the sublime: irrationality, inherent unpredictability and intangibility of IT/IS product (software, system and cyberspace) all serve to render the soil underpinning such projects fertile for unfounded managerial enthusiasm and unchecked imagination, opportunism and the pursuit of players' own agendas.

Collaborative ethics involves "the calculation of individual interest in a context in which human beings are obliged to cooperate with each other" (Hutchings, 2010, p.48). But, in a wider context, through the process of globalisation, we are economically, socially, culturally and politically "embedded in, and depend on, relations with strangers from all parts of the world" (Hutchings, 2010, p.4). What needs to be put in place is a process through which: "...parties who see different aspects of a problem can constructively explore their differences and search for solutions that go beyond their own limited vision of what is possible." (Gray, 1989). To change 'undesirable' patterns of joint action, a new shared thematic framework needs to be enacted (Suchman, 2000) through processes of communicative and powerrelating, drawing on new themes and symbols, towards creating and stabilising a coherent set of practices in the context of software development and IT/IS implementation.

\section{Overall shift in approach}

The shift we propose departs from more common normative/rational approaches to the nature of project governance, to embrace the psycho-social dimensions of decision-making and the operation of power and interaction among project parties, without discarding the pragmatic complexity and ethical ambiguity of glory projects in the name of rationality (March, 1989). Project governance and decision-making should be studied from multiple theoretical positions, so that 'getting investments right' is treated as a problem of delivering economies, as well as relationally. Such an approach to governance would need to be both moral and ethical in nature, and driven by performance-enhancing possibilities, participation and future-oriented options, rather than by 'explicit rules governing practices' (Holt and Rowe, 2000). Project governance from a relationship perspective would require control mechanisms 
to be not just structurally formalised, but also socialised (i.e. a combination of contractual and informal mechanisms), joining together the endeavours of two otherwise separate functions: project implementation and project governance, when there is no value-equilibrium.

With the governance of a mega-project, we need to create a collective identity as a community of inquiry and encourage the collaborators to reflect together on the quality of their participation (Raelin, 2001). In dealing with project unpredictability and complexity, participant reflection should take on a public form and, in turn, influence the emergence of collaborative learning practices within the governance coalition.

Building on Taggert and Silbey's (1986) rather cynical proposition of a political development cycle of IT/IS projects, and modified by the insights from our own analysis, we argue that the following is empirically justifiable as a pragmatically helpful framework in understanding the relational essence and stages of managerial failure commonly associated with mega-project governance: 'initial wild enthusiasm, emerging disillusionment, total confusion, search for the guilty, punishment of the innocent, and promotion of villains, trouble-makers, opportunists and non-participants; all of these in contrast to the conventional view of the rational project life cycle model.'

Our overall approach has combined pragmatic theorising with concrete empirical analysis to address the challenges of governing a complex project in a critical and constructive way, focusing on the issues of context, values and power as related to the local, national and global aspects of project governance and its key pillars - quality, safety and basic trust intrinsic to human relationships. Inevitably, mega-projects have global scope, both in terms of the problem they are supposed to overcome (e.g. sustainability imperative, instant communication, efficiency), and in terms of the implications (due to the inter-connectivity and inter-dependency of our globalised world). They are likely to be more numerous, controversial, costly, unpredictable and problematic in the future, reinforcing both their complexity, and the governance challenge they present.

\section{References}

Bowers, S., 2011. NHS software provider CSC may get cash lifeline. The Guardian,26 Sep..

Bresnen, M. and Marshall, N., 2000 Motivation, commitment and the use of incentives in partnerships and alliances. Construction Management and Economics, 18, pp.587-598.

British Computer Society,2006. The Way Forward for NHS Health Informatics: Where should NHS Connecting for Health (NHS CFH) go from here? The British Computer Society Health Informatics Forum Strategic Panel, December.

Braun B and Castree N (1998) Remaking Reality: Nature at the Millennium London and New York: Routledge 
Cabinet Office, 2011. Major Projects Authority Programme Assessment Review of the National Programme for IT.

Cadle, J. and Yeates, D., 2001. Project Management for Information Systems. 3rd ed. Harlow, UK: Pearson Education.

Cavendish, C., 2012. We're wasting billions. Lets break the habit. The Times, London, 12 Jan..

Chia, R., 2002. Essai: Time, Duration, and Simultaneity: Rethinking Process and Change in Organizational Analysis. Organization Studies, 23 (6), pp.863-868.

Cicmil, S. and Marshall, D., 2005. Insights into collaboration at project level: complexity, social interaction and procurement mechanisms. Building Research and Information, 33 (6),pp. 523-535.

Cicmil, S., Williams, T., Thomas, J. and Hodgson, D., 2006. Rethinking Project Management: Researching the Actuality of Projects. International Journal of Project Management: Special issue on Rethinking project management, , November, 24, pp. 675-686.

Cicmil, S., Cooke-Davies, T., Crawford, L. and Richardson, K., 2009. Exploring the Complexity of Projects: Implications of Complexity Theory for Project Management Practice. Research Monograph, PMI: USA.

Clegg, S., Pitsis, T., Rura-Polley, T. and Marossheky, M., 2002. Governmentality Matters: Designing an Alliance Culture if Inter-organisational Collaboration for Managing projects. Organisation Studies, 3 (3), pp.317-337.

Clegg, S., Pitsis, T., Marossheky, M. and Rura-Polley, T., 2006. Making the future perfect: constructing the Olympic dream. In: D.Hodgson and S.Cicmil, eds. Making Projects Critical. Basingstoke, UK and New York, USA: Palgrave McMillan :, pp.265-293.

Drummond, H., 1994. Too Little Too Late: A Case Study of Escalation in Decision Making. Organization Studies, 15 (4), pp. 591-607.

Drummond, H., 1999. Are we any closer to the end? Escalation and the case of Taurus. International Journal of Project Management, 17(1), pp.11-16.

Ehealthinsider ,2011. Available at: 〈http://www.ehi.co.uk/> (Accessed 10 January 2011).

Flyvbjerg, B., 1998. Rationality and Power: Democracy in Practice. Chicago, IL: University of Chicago Press.

Flyvbjerg, B., 2001. Making Social Science Matter: Why social inquiry fails and how it can succeed again (reprinted 2003); Cambridge: Cambridge University Press.

Flyvbjerg, B., 2008. Public planning of mega-projects: overestimation of demand and underestimation of costs. In: H. Priemus, B. Flyvbjerg and B. van Wee, eds. Decision- 
Making on Mega-Projects: Cost-Benefit Analysis, Planning and Innovation. Cheltenham: Edward Elgar Publishing Ltd, pp.120-144.

Flyvbjerg, B., Bruzelius, N. and Rothengatter, W., 2003. Megaprojects and Risk: An anatomy of ambition. Cambridge, UK: Cambridge University Press.

Flyvbjerg, B., Holm, M. S. and Buhl, S., 2005. How (In)accurate are Demand Forecasts in Public Works Projects - The Case of Transportation. Journal of American Planning Association, Spring, 71(2), pp.131-146.

Ford, R., 2011. Fire service IT project 'was deeply flawed'. The Times, 20 Sep. News section, p.11.

Grabher, G., 2002. Cool Projects, Boring Institutions: Temporary Collaboration in Social Context. Regional Studies, 36 (3), pp.205-214.

Gray, B., 1989. Collaborating: finding common ground for multiparty problems. San Francisco: Jossey Bass.

Hansard, 2011. Extracts from speech by Richard Bacon, MP; 14 June 2011.

Hart, O., 1995. Corporate governance: Some theory and implications. The Economic Journal [105:430] pp.678-689.

Hodgson, D. and Cicmil, S. eds., 2006. Making Projects Critical. Basingstoke, UK and New York, USA: Palgrave McMillan.

Holt, R. and Rowe, D., 2000. Total quality, public management and critical leadership in civil construction projects. International Journal of Quality and Reliability Management, 17 (4/5), pp.541-543.

Hutchings, K., 2010. Global Ethics - An Introduction. Cambridge, UK: Polity Press.

Ive, G. and Rintala, K., 2006. The economics of relationships. In: S.Pryke and H.Smyth, eds. The Management of Complex Projects - A Relational Approach. Oxford, UK: Blackwell Publishing. Ch. 12, pp.282-302.

Kennedy, D., Pitel, L. and Homann, I., 2011. Dead wrong, the software that NHS says it just can't discuss. The Times, 9 Dec..

King's Fund,(2007.Our Future Health Secured? A review of NHS funding and performance. The King's Fund.

Klakegg, O.J., Williams, T. and Magnussen, O. M., 2009. Governance frameworks for public project development and estimation. Newton Square, USA: Project Management Institute.

Knights, D., Noble, F., Vurdubakis, T. and Willmott, H., 2001. Chasing Shadows: Control, Virtuality, and the Production of Trust. Organization Studies, 22(2), pp.311-336. 
Laurance, P., 2010. Doctors' illegible notes will be with us for years. The Independent, 19 Jan..

Lewis, L., 2011a. Cracks widen in Beijing's grand vision for the future. The Times, July 9. World section, p.43.

Lewis, L., 2011b. High-speed work spoils Beijing's fast track to future. The Times, Aug 30., Business section, p.37.

Loosemore, M., 2006. Managing project risks. In: S.Pryke and H.Smyth, eds. The Management of Complex Projects - A Relational Approach'. Oxford, UK: Blackwell Publishing. Ch. 8, pp.187-204.

March, J. G., 1989. Decisions and Organisations, Oxford :Basil Blackwell..

McManus, J. and Wood-Harper, T., 2008. A Study in Project Failure. The Chartered Institute for IT, June.

Miller, R. and Lessard, D., 2008. Evolving strategy: risk management and shaping of megaprojects. In: H.Premus, B,Flyvbjerg and B.Van Wee, eds. Decision-Making on Mega Projects: Cost-Benefit Analysis, Planning and Innovation Cheltenham, UK :Edward Elgar, pp.145-172.

Monks, R.A.G. and Minow, N., 1995. Corporate Governance. John Wiley \& Sons.

National Audit Office ,2006. The National Programme for IT in the NHS, 16 June.

Nye, D., 1994. American Technological Sublime. Cambridge, MA: The MIT Press

O'Driscoll, S. and O'Connell, D., 2011. Supplier knew NHS tech project doomed. The Sunday Times, 23 Oct. .

PAC ,2007. The National Programme for IT in the NHS .House of Commons Public Accounts Committee report, Department of Health:.

PAC, 2009. The National Programme for IT in the NHS: Progress since 2006.

House of Commons Public Accounts Committee report.

PAC, 2011. The National Programme for IT in the NHS: an update on the delivery of detailed care records systems. House of Commons Public Accounts Committee report.

Pietz, W.,2002. Material Considerations: On the Historical Forensics of Contract. Theory, Culture \& Society, 19 (5/6), pp.1-21.

Pitel, L., Smyth, C. and Kennedy, D., 2011. American 'cowboys' blamed for NHS fiasco. The Times, 9 Dec..

Priemus, H., Flyvbjerg, B. and van Wee, B., 2008. Decision-Making on Mega-Projects: CostBenefit Analysis, Planning and Innovation. Cheltenham: Edward Elgar Publishing Ltd. 
Pryke, S. and Smyth, H., 2006. The Management of Complex Projects - A Relational Approach. Oxford, UK: Blackwell Publishing.

Raelin, J. A., 2001. Public reflection as the basis of learning. Management_Learning, 32 (1), pp.11-30.

Rehn, A., 2006. The Luxury of Projects: Excess and Irrational Exuberance in a Projectified Society, MPC 3 Key-Note Address; EIASM $3^{\text {rd }}$ Making Projects Critical Workshop, 11-12 December 2006. Manchester: Manchester Business School.

Ritter, T., 2008.Secret report on NPfIT Lorenzo: hundreds of issues. Computer Weekly, 19 June.|

Ross and Staw, 1986.Expo 86: an escalation prototype. Administrative Science Quarterly, 31, pp.379-391.

Samset, K., 2008. How to overcome major weaknesses in mega-projects: the Norwegian approach. In: H.Premus, B.Flyvbjerg and B.Van Wee,eds. Decision-Making on Mega Projects: Cost-Benefit Analysis, Planning and Innovation'. Cheltenham, UK: Edward Elgar,: pp.173-188.

Sheridan, M., 2011. Scandal tips China rail boom off racks. The Sunday Times, 28Aug., News section, p.31

Smyth, H., 2006. Measuring, developing and managing trust in relationships. In: S.Pryke and H.Smyth, eds. The Management of Complex Projects - A Relational Approach. Oxford, UK :Blackwell Publishing. Ch 4, pp.97-120.

Smyth, C. and Kennedy, D., 2011. Zombie contracts' likely to mean suppliers at fault will benefit most. The Times, 9 Dec.

Stacey, R., 2001. Complex Responsive Processes in Organizations: Learning and knowledge creation. London: Routledge.

Stacey, R., 2003. Strategic Management and Organizational Design - The Challenge of Complexity .4th ed. Harlow :FT Prentice Hall.

Staw, B.M. and Ross, J., 1978. Commitment to a policy decision: a multi-theoretical perspective. Administrative Science Quarterly, 23, pp.40-64.

Suchman, L., 2000. Organising Alignment: A Case of Bridge-building. Organization, 7 (2), pp.311-327.

Sydow, J. and Staber, U., 2002. The Institutional Embeddedness of Project Networks: The Case of Content Production in German Television. Regional Studies, 36 (3), pp.215227. 
Taggert, W.M. and Silbey, V., 1986. Informational Systems: People and Computers in Organisations. Boston, USA: Allyn \& Bacon.

Thomsett, R., 1980. People and Project Management. New York: Yourdon inc.

Trapenberg-Frick, K., 2008. The cost of the technological sublime: daring ingenuity and the new San Francisco-Oakland Bay Bridge. In: H. Priemus, B. Flyvbjerg and B. van Wee, eds. Decision-Making on Mega-Projects: Cost-Benefit Analysis, Planning and Innovation. Cheltenham: Edward Elgar Publishing Ltd, pp.239-262.

Turner, J.R. and Cochrane, R.A., 1993. The goals and methods matrix: coping with projects for which the goals and /or methods of achieving them are ill-defined. International Journal of Project Management, 11 (2),pp. 93-101.

Van Marrewijk, A., Clegg, S.R. and Pitsis, T.S., 2008. Managing public-private megaprojects: Paradoxes, complexity and project design. International Journal of Project Management, 26, pp.591-600.

Wachs, M., 1989. When planners lie with numbers. Journal of the American Planning Association, 55 (4), pp.476-9.

Weick, K., 2002. Essai. Organization Studies, 23(6),pp.863-868. 